\title{
Bilateral indwelling pleural catheter for hepatic hydrothorax
}

\author{
Rossella D’Amato, Luisa E Eiroa González, Ana Isabel Hernández Méndez
}

Pneumology Department, Hospital Universitario Nuestra Senora de la Candelaria, Santa Cruz de Tenerife, Spain

\section{Correspondence to} Dr Rossella D'Amato, rossdam@hotmail.it

Accepted 21 December 2016

\section{SUMMARY}

A 68-year-old man with alcoholic liver cirrhosis and portal hypertension was admitted due to ascites. Bilateral severe hepatic hydrothorax did not resolve despite sodium restriction, and diuretic treatment, requiring repeated thoracentesis for relief of dyspnoea. Curative options, as transjugular intrahepatic portosystemic shunt and liver transplantation were both contraindicated. An attempt of pleurodesis was ineffective. Bilateral insertion of tunnelled pleural catheter allowed symptom control and home discharge. After 6 months, bilateral stable pleurodesis has been achieved and patient is still free from dyspnoea.

\section{BACKGROUND}

Tunnelled indwelling pleural catheter is a validated treatment option for malignant pleural effusion. However, its role in recurrent non-malignant pleural effusion is less established. Hepatic hydrothorax $(\mathrm{HH})$ is described in up to $15 \%$ of patients with end-stage liver disease, ${ }^{1}$ with significant impact on morbidity and quality of life in patients with end-stage liver disease. Options for patients who are not candidate to curative treatments, that is, liver transplantation, are limited and often ineffective. We present a case of $\mathrm{HH}$ who was successfully treated with bilateral indwelling pleural catheter, allowing symptoms control and management in the outpatient setting.

\section{CASE PRESENTATION}

A 68-year-old man diagnosed with alcoholic liver cirrhosis, with portal hypertension-related complications: grade F3 esophageal non-bleeding varices and moderate gastropathy, reported an increase in abdominal circumference and shortness of breath in the previous 2 weeks. Physical examination indicated decreased breath sounds in the left hemithorax, with dullness on percussion; vascular spiders and a positive puddle sign were observed.

Laboratory test showed sodium level $129 \mathrm{mmol} / \mathrm{L}$, creatinine $1.34 \mathrm{mg} / \mathrm{dL}$, alkaline phosphatase $76 \mathrm{U} / \mathrm{L}$, $\gamma$-glutamyl transferase $88 \mathrm{U} / \mathrm{L}$; haemoglobin was $12.5 \mathrm{~g} / \mathrm{dL}$ with a mean corpuscular volume of $102 \mathrm{fL}$; his white cell count and platelet count as well as aspartate aminotransferase and alanine aminotransferase were within normal limits.

A chest radiography (CXR) confirmed the clinical suspicion of a submassive left pleural effusion (PE) (figure 1A). Left thoracentesis was performed, draining $1500 \mathrm{cc}$ of clear serous pleural fluid. Laboratory analysis revealed a transudative PE, with negative microbiological cultures and benign cytology. A spontaneous bacterial peritonitis was ruled out by paracentesis. CT scan showed left severe PE, cirrhotic liver without any focal lesion, portal vein thrombosis and severe ascites. CT scan findings, along with a normal bronchoscopic exploration of the airway, definitely ruled out lung and liver malignancy. On the basis of these findings, we confirmed a diagnosis of $\mathrm{HH}$.

A combination of furosemide and spironolactone was started and progressively increased in a stepwise manner, in order to achieve a renal excretion of at least $120 \mathrm{mEq}$ sodium/day. In the following days, despite sodium restriction and diuretic treatment, he developed bilateral PE, predominantly left-sided, requiring repeated left thoracentesis for relief of dyspnoea; furthermore, regardless of timely albumin infusions, he experienced deterioration in his renal function, which further limited volume depletion treatment.

\section{TREATMENT}

Owing to refractory $\mathrm{HH}$, we considered the option of transjugular intrahepatic portosystemic shunt (TIPS), but the finding of portal vein thrombosis contraindicated the procedure. Liver transplantation and repair of diaphragmatic defects through video-assisted thoracoscopic surgery were contraindicated because of the high comorbidity-based surgical risk. In the end, we settled on insertion of a tunnelled pleural catheter (TPC; PleurX System) on the left side.

After few days, the patient experienced progressive dyspnoea, in spite of daily drainages ( $\sim 700 \mathrm{~mL} /$ day) through the left TPC; a CXR showed worsening severe right $\mathrm{PE}$ and complete re-expansion of the left lung (figure 1B). Talc slurry pleurodesis, through an $8 \mathrm{~F}$ chest tube in the right pleural cavity, was initially effective in reducing right PE, allowing chest tube removal and patient discharge from the hospital.

During the following weeks, a progressive decrease in the amount of drainage from the left catheter was observed; after ruling out drain obstruction or dislocation, spontaneous pleurodesis was confirmed (20 days after TPC insertion); nevertheless, right $\mathrm{PE}$ relapsed, hence we decided to insert a TPC in the right side too (figure 2A).

\section{OUTCOME AND FOLLOW-UP}

At present, 6 months after the insertion of the second TPC, patient is still free from left PE, and the amount of drainage from the right side is progressively reducing (figure $2 \mathrm{~B}$ ). 

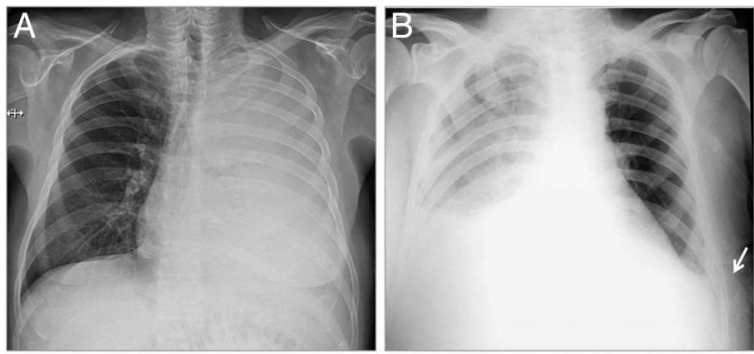

Figure 1 (A) Posteroanterior projection of chest X-ray showing complete white-out of left hemithorax, with slight mediastinal shift. CT scan confirmed severe left pleural effusion. (B) New onset right-sided pleural effusion. After pleural catheter insertion (arrow), left lung is fully expanded and only mild residual effusion is observed in the costophrenic angle.
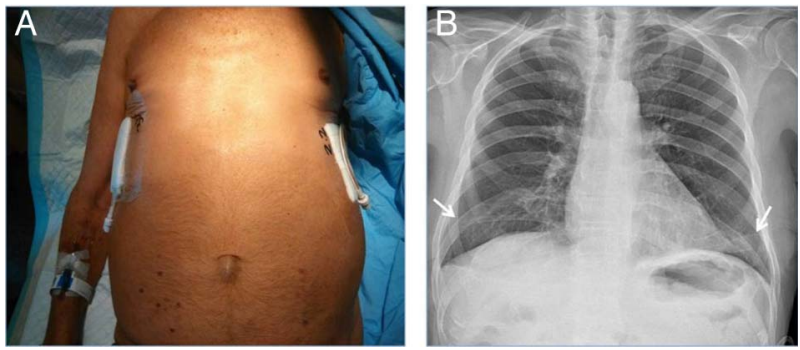

Figure 2 (A) Bilateral tunnelled pleural catheter. (B) Chest X-ray showing tunnelled pleural catheters (arrows) without residual pleural effusion.

\section{DISCUSSION}

Nearly $20 \%$ of $\mathrm{HH}$ are refractory to salt restriction and diuretics, requiring repeated thoracentesis for relief of symptoms that expose the patient to the risk of complications such as pneumothorax, haemothorax or re-expansion pulmonary oedema. In patients with refractory $\mathrm{HH}$, liver transplant is the curative treatment; for patients who are not candidate or as bridge to transplant, TIPS can be performed as alternative, with high success rate reported in the literature. ${ }^{2}$ Surgical repair of diaphragmatic defects prevent the transfer of ascitic fluid across the diaphragm, but data concerning feasibility are scarce. TPC seems to be a reasonable option for patients who are not eligible for the latter strategies. It has been reported to be effective in the management of malignant recurrent PE, although scientific evidence is weaker in non-malignant conditions. ${ }^{3-5}$ One of the most notable point in its favour is the possibility for early hospital discharge and home care management; however, this option should imply a great effort in order to improve education of patients and their caregivers. In this view, concerns exist regarding the risk of TPC-related pleural infection, which has been reported up to $12 \%$ of patients. ${ }^{6}$ Pathogenesis of this latter phenomenon has not been clarified; it seems related to bacterial migration from the skin, as Staphylococcus aureus is the most represented pathogen in pleural fluid culture and, notably, could be mainly associated with inadequate catheter aftercare and deficient immune system of the host, rather than to the insertion procedure. ${ }^{6}$ Prolonged drainage through a chest tube has been associated with electrolyte loss, protein depletion and impaired immunological function. Some authors suggest that the intermittent removal of small amounts of fluid via the TPC significantly reduces the chance of renal dysfunction, commonly associated with the massive fluid loss through a conventional chest tube. Currently, data reporting the effect of IPC drainage, with respect to conventional chest tube, on nutrition and immunology are scarce. In our patient, we did not perform any systematic pleural fluid culture as we did not observe any sign of infection; on the other hand, an oral protein supplementation with liver-adapted solution was provided, as a mild drop in albumin level was observed. While the success rate of chemical pleurodesis in this context remains low, ${ }^{7}$ spontaneous pleurodesis after TPC placement has been frequently described in case series. ${ }^{4}$ Interestingly, patients with non-malignant pleural effusion seem to have significantly higher time to pleurodesis compared with malignant aetiology $(110.8+41$ days vs 36 +12 days), and patients with $\mathrm{HH}$ have shorter time to spontaneous pleurodesis compared to congestive heart failure. Increased levels of circulating inflammatory mediators in persons with cirrhosis could be responsible for rapid pleural symphysis. ${ }^{4}$

\section{Patient's perspective}

Patient definitely appreciated the option of home care management. After a brief education course on how to drain at home with the PleurX system, the patient and his family felt confident with the drainage system.

\section{Learning points}

- Hepatic hydrothorax $(\mathrm{HH})$ contributes to increase morbidity in patients with end-stage liver disease.

- This case, in line with recent literature, provides evidence about effectiveness and safety of tunnelled pleural catheter (TPC) in $\mathrm{HH}$.

- In patients not eligible for curative treatment, TPC insertion should be considered as alternative strategy to provide symptoms control and management in the home care setting.

Contributors RD'A contributed to study design and the draft of the article. LEEG and AlHM were involved in revising and editing the final report. All authors have contributed to the manuscript.

Competing interests None declared.

Patient consent Obtained.

Provenance and peer review Not commissioned; externally peer reviewed.

\section{REFERENCES}

1 Chen TA, Lo GH, Lai KH. Risk factors for spontaneous bacterial empyema in cirrhotic patients with hydrothorax. J Chin Med Assoc 2003;66:579-86.

2 Siegerstetter $V$, Deibert $P$, Ochs $A$, et al. Treatment of refractory hepatic hydrothorax with transjugular intrahepatic portosystemic shunt: long-term results in 40 patients. Eur J Gastroenterol Hepatol 2001;13:529-34.

3 Bhatnagar R, Reid ED, Corcoran JP, et al. Indwelling pleural catheters for non-malignant effusions: a multicentre review of practice. Thorax 2014;69:959-61.

4 Chalhoub M, Harris K, Castellano M, et al. The use of the PleurX catheter in the management of non-malignant pleural effusions. Chron Respir Dis 2011;8:185-91.

5 Srour N, Potechin R, Amjadi K. Use of indwelling pleural catheters for cardiogenic pleural effusions. Chest 2013;144:1603-8.

6 Lui MM, Thomas R, Lee YC. Complications of indwelling pleural catheter use and their management. BMJ Open Respir Res 2016;3:e000123.

7 Rodriguez-Panadero F, Antony VB. Pleurodesis: state of the art. Eur Respir J 1997:10:1648-54.

8 Kilburn JP, Hutchings J, Misselhorn D, et al. Use of indwelling tunneled pleural catheters for the management of hepatic hydrothorax. Chest 2010;138:418A. 
Copyright 2017 BMJ Publishing Group. All rights reserved. For permission to reuse any of this content visit http://group.bmj.com/group/rights-licensing/permissions.

BMJ Case Report Fellows may re-use this article for personal use and teaching without any further permission.

Become a Fellow of BMJ Case Reports today and you can:

- Submit as many cases as you like

- Enjoy fast sympathetic peer review and rapid publication of accepted articles

- Access all the published articles

- Re-use any of the published material for personal use and teaching without further permission

For information on Institutional Fellowships contact consortiasales@bmjgroup.com

Visit casereports.bmj.com for more articles like this and to become a Fellow 